\title{
The online Varve Image Portal: A new tool for studying annually laminated sediments
}

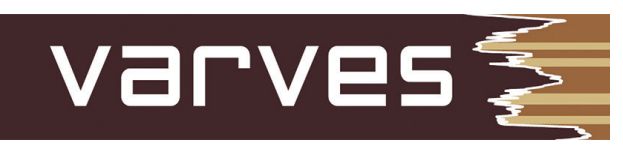

Bernd Zolitschka ${ }^{1}$, P. Francus ${ }^{2,3}$, A.E.K. Ojala ${ }^{4}$, A. Schimmelmann ${ }^{5}$ and C. Telepski ${ }^{6}$

\begin{abstract}
Annually laminated (i.e. varved) sediment sequences are important natural archives of paleoenvironmental conditions that offer an accurate indication of time span in absolute years, exceptional high (up to seasonal) temporal resolution, and the possibility of calculating sediment flux rates. During the $19^{\text {th }}$ International Sedimentological Congress 2014 in Geneva, Switzerland, a new tool for the dissemination of visualized information from annually laminated sediments - the online Varve Image Portal - was officially launched. This new website displays images of various varve types based on contributions from the scientific community. This online resource is now fully operational and growing and we are asking for input from scientists around the world (Fig. 1). Please contribute your additional varve images from new and published sites together with metadata to Bernd Zolitschka: zoli@uni-bremen.de
\end{abstract}

\section{Improving varve analysis}

Although the scientific community has come to appreciate the value provided by both marine and lacustrine annually laminated sediments, there remains a widespread lack of awareness about the need to provide careful evidence that finely laminated sediments are truly varved before exploiting lamina counts for geochronological purposes and environmental interpretations through time.

Such a misconception between varved and finely laminated sediments might partially originate from the history of the expression "varve", a term introduced by the Swedish geologist De Geer during the early $20^{\text {th }}$ century to describe minerogenic proglacial lake sediments of Sweden as annually laminated. Later on, the term varve was extended to other lacustrine as well as marine sediment types with preserved annual successions and seasonal sub-laminae. The large diversity of sediments featuring a varved character sometimes led to the misconception that most, if not all finely laminated sediments must be varved, which clearly is not the case.

The Varve Image Portal aims to provide exemplary visual information regarding the compositional and structural diversity of varved sediments, and to assist, train and guide researchers in the critical judgment of the relative timing of (sub)-laminae and

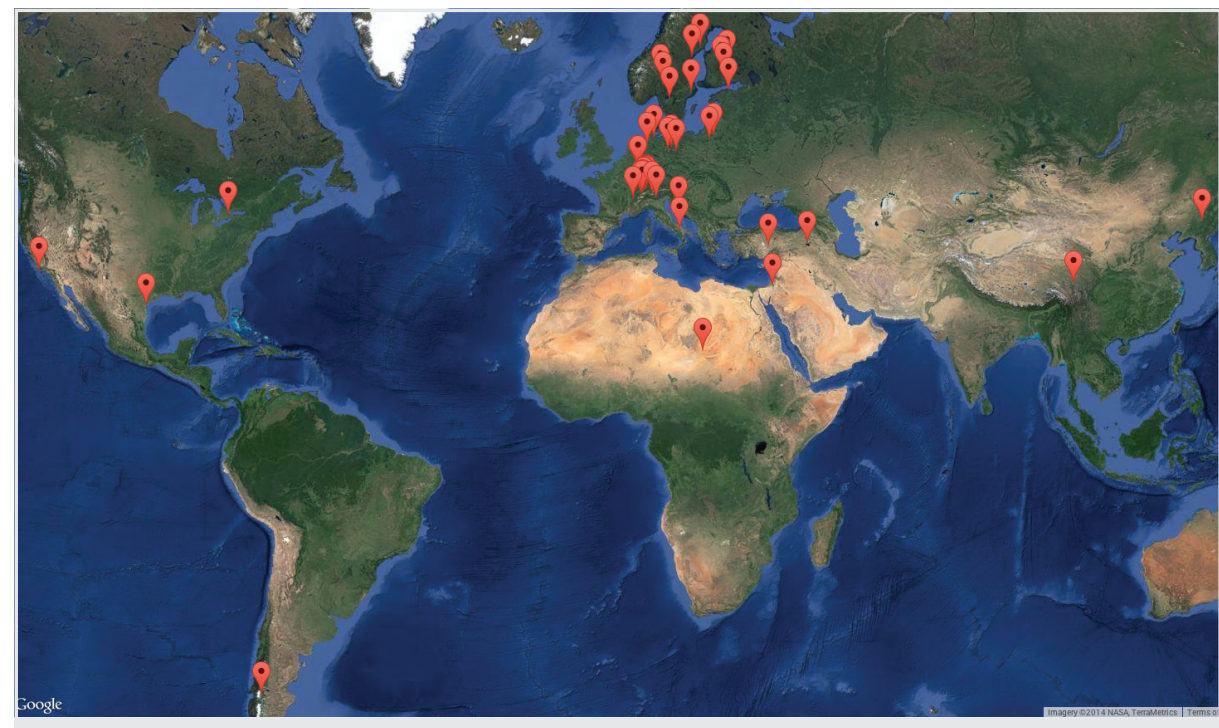

Figure 1: Screenshot from the Varve Image Portal documenting the current global coverage of varve images.

how to constrain their geochronological potential. The Varve Image Portal also intends to disseminate existing image information about varves and to facilitate the efforts of students and young scientists to get acquainted with the challenging topic of finely laminated sedimentary structures. It is accessible via

http://pages-igbp.org/workinggroups/ varves-wg/varves-image-library

\section{Using the portal}

Each varve image of this online database is accompanied by metadata including information about the study site, satellite and terrestrial images as well as references with DOI links to publications reporting the specific varve record.

The Varve Image Portal has three different search functionalities: (1) A map-based search, (2) a search based on a genetic concept where varves are compositionally categorized as clastic, biogenic, endogenic (incl. evaporitic) and mixed, and (3) an alphabetic search of site names.

This online tool offers exemplary views on many different aspects of varved sediment structures including macroscopic images of gravity and freeze cores. Microscopic images with different magnifications provide examples in normal and polarized light. Scanning electronic microscope images, radiographs and images combined with analytical data or interpretations complete this internet-based resource. Additionally, general information about varves as well as links to varve-related and methodologically relevant websites are provided. Finally, the Varve Image Portal provides easy access to varve reviews, to other iconic publications closely linked to varve studies as well as to publications related to methods and techniques that apply to the investigation of varved sediment records.

\section{AFFILIATIONS}

IInstitute of Geography, University of Bremen, Germany

${ }^{2}$ Institut National de la Recherche Scientifique, Québec, Canada

${ }^{3}$ GEOTOP-UQAM-McGill, Montréal, Canada ${ }^{4}$ Geological Survey of Finland, Espoo, Finland ${ }^{5}$ Department of Geological Sciences, Indiana University, Bloomington, USA

'PAGES International Project Office, Bern, Switzerland CONTACT

Bernd Zolitschka: zoli@uni-bremen.de 